\title{
Beyond STRs: The Role of Diallelic Markers in Forensic Genetics
}

\author{
Peter M. Schneider \\ Institute of Legal Medicine, Medical Faculty, University of Cologne, Germany
}

\section{Keywords}

Short tandem repeat systems - Single nucleotide polymorphism - Insertion/deletion polymorphism . Kinship testing · Forensic DNA analysis

\section{Summary}

Short tandem repeat (STR) polymorphisms have been firmly established as standard DNA marker systems since more than 15 years both in forensic stain typing as well as in paternity and kinship testing. However, when analyzing genetic relationships in deficiency cases, STRs have a couple of disadvantages due to the sometimes poor biostatistical efficiency as well as the possibility to observe one or more genetic inconsistencies that could also be explained by mutational events. In such situations, additional robust markers with negligible mutations rates such as single nucleotide polymorphisms (SNPs) and insertion/deletion markers (indels) can be used as adjuncts to provide decisive genetic information in favor for or against the assumed relationship. Both SNPs and indels can now be typed more easily using multiplexes of up to 50 loci based on fragment length analysis on instruments available in all routine forensic and paternity testing laboratories, thus making it possible to extend the range of markers beyond the currently used STRs.

Forensic genetics of human DNA polymorphisms has come a long way since the first application of 'DNA fingerprinting' was described by Sir Alec Jeffreys in 1985 [1, 2]. Following their discovery, multiple generations of genetic marker sys-

\section{Schlüsselwörter}

Short-Tandem-Repeat-Systeme · Single-NucleotidePolymorphismus · Insertions-/Deletions-Polymorphismen . Verwandtschaftsanalyse · Forensische DNA-Analyse

\section{Zusammenfassung}

"Short tandem repeat»(STR)-Polymorphismen sind als Standard-Typisierungssysteme sowohl in der forensischen Spurenkunde als auch in der Abstammungsuntersuchung seit mehr als 15 Jahren fest etabliert. Bei der Untersuchung von Abstammungen in komplexen Defizienzfällen haben STR-Systeme jedoch einige Nachteile durch die zum Teil nur geringe biostatistische Effizienz sowie durch das Auftreten einer oder mehrerer Ausschlusskonstellationen, die auch durch Mutationen erklärt werden könnten. In solchen Situationen sind robuste genetische Marker mit vernachlässigbar kleinen Mutationsraten wie Single-Nucleotide-Polymorphismen (SNPs) und Insertion-/Deletionsmarker (Indels) als Ergänzung notwendig, um eindeutige Informationen für oder gegen die untersuchte Verwandtschaftshypothese zu erhalten. Sowohl SNPs and als auch Indels können mittlerweile relativ einfach mit Hilfe von Multiplexen von bis zu 50 Markern auf der Basis der Fragmentlängenanalyse mit Hilfe von Instrumenten typisiert werden, die in allen forensischen Laboren vorhanden sind, so dass der Umfang der zur Analyse verfügbaren Polymorphismen um robuste Marker jenseits der aktuell eingesetzten STR-Systeme ergänzt werden kann.

tems have been described and new DNA typing technologies introduced. Short tandem repeat (STR) markers have already been studied since more than 20 years ago, but their breakthrough for general acceptance as 'work horse' in forensic ge-

\section{KARGER \\ Fax +497614520714 \\ Information@Karger.de}

www.karger.com (c) 2012 S. Karger GmbH, Freiburg

$1660-3796 / 12 / 0393-0176 \$ 38.00 / 0$

Accessible online at:

www.karger.com/tmh
Prof. Dr. Peter M. Schneider

Institute of Legal Medicine

University of Cologne

Melatengürtel 60/62, 50823 Köln, Germany

Tel. +49 221 47888-222, Fax -370

peter.schneider@uk-koeln.de 
netics was linked to the introduction of automated capillary gel electrophoresis, and the availability of affordable and easy-to-use equipment for the detection of DNA fragment length polymorphisms, together with the development of fluorochrome-labeled multiplex PCR-based STR typing kits [3-5].

Following the introduction of automated STR typing, the two main applications - criminal casework and genetic relationship testing - have made 'quantum leaps' regarding the discrimination power, the robustness and reliability, and the efficiency both for economical as well as for practical reasons. In criminal casework, national DNA databases have changed the way of carrying out investigations in all cases where biological stains from unknown perpetrators could be collected. In Europe, the first national DNA database was established in England and Wales in 1995 [6]. In the USA, the Combined DNA Index System (CODIS) was gradually introduced by the FBI since 1989, and was formally created by the DNA Identification Act of 1994 and launched nationally in 1998. Since then, most of the European countries as well as many more countries from all over the world have introduced collections of DNA profiles from unsolved crime cases as well as from suspects and/or convicted offenders [7]. It has become one of the most efficient investigative tools leading to thousands of "cold hits' in crime cases where no suspect could be identified following conventional investigations. On the other hand, numerous cases have been reported about individuals who had been convicted at a time when DNA typing was not yet available, but who have claimed to be innocent, and could be exonerated with the help of new DNA results [8]. It must be generally stated that more persons have been exonerated than convicted using DNA typing, as most suspects are excluded already very early on in the investigation. In the context of searching a criminal DNA database, if the crime scene profile does not match any of the persons who are in the national database, the police know immediately that the perpetrator must be an unknown person not included in the database.

In genetic relationship testing, the introduction of STRs has largely facilitated the analysis of standard scenarios such as paternity cases. STRs have quickly replaced both conventional blood group and serum protein markers as well as single locus variable number of tandem repeats (VNTR) probes, the first generation of hybridization-based DNA typing systems which were quite powerful but cumbersome to use [9, 10]. Using STRs, the vast majority of cases can be decided conclusively leading either to an exclusion based on multiple genetic incompatibilities between alleged father and child, or to an inclusion with a very high probability of paternity [11, 12]. Furthermore, the introduction of Y-chromosomal STR markers in cases of a postulated relationship in the paternal lineage has further enhanced the usefulness, extending its application into the area of genealogy where male relatives can be tested being many generations apart [13-15]. In addition, $\mathrm{X}$-chromosomal STRs have been developed that are of par- ticular usefulness in deficiency cases where e.g. the alleged father is not available for testing [16, 17].

However, a price has to be paid for the simplicity and ease of using STR markers [18]. There are two main disadvantages of these genetic polymorphisms that have to be dealt with: first, the individual biostatistical efficiency of the most commonly used STR markers, as measured e.g. by its exclusion power in paternity cases, is limited (typically between 0.5 and 0.7 in trio cases); and second, STRs exhibit significant mutation rates of up to 0.05 which can cause major problems in cases where the mother is not available for testing or when a relative of the tested man has to be considered as alternative father [19]. It has been demonstrated that serious problems may be encountered if e.g. the mother has been deliberately excluded from genetic testing (the so-called 'motherless case'). This been demonstrated convincingly in a number of retrospectives studies on trio cases with proven paternity using 15 STRs, where the mother's typing results were omitted, and the cases were re-analyzed. As a result, in 5 out of 125 child/uncle pairs, no STR mismatches were found, and paternity probabilities between $99.9726 \%$ and $99.9970 \%$ (paternity indices between 3.652 and 33.545) were calculated [20, 21]. In addition, STRs are rapidly becoming inefficient if distant relationships are being tested such as putative cousins or even siblings or half-siblings, without genetic information about the parents, especially if they are a male-female pair so that gonosomal markers are not informative on the paternal side. At this level, the probability of observing a shared STR allele is very often higher based on the common population frequency of this particular allele than based on the assumed genetic relationship, and consequently will reduce the resulting likelihood [22].

Mutations can introduce further complications, as they will result in a significantly lower probability for paternity, and may require the testing of additional markers for compensation. Already cases with three mutations have been described when a total of up to 30 markers have been tested [23, 24]. The resulting paternity index which included mutation calculations in these cases still indicated strong evidence for paternal relationship, but of course a major effort for inclusion of additional markers was required. In other situations involving the investigation of a deficiency case, or in a scenario with relatives as putative fathers, mutations will further complicate the analysis so that the result could remain inconclusive without additional markers [25].

These properties of STR markers could be compensated by genetic marker systems which are either more powerful or more abundant and less prone to mutation events. Whereas new markers of the first category may be difficult to identify (the single-locus VNTR systems were from this type, but have been abandoned mostly for practical reasons; see above), markers of the second category are available indeed in more than abundant numbers: the single nucleotide polymorphisms (SNPs) and the insertion/deletion markers (indels). Both 
types of markers had binary polymorphisms, i.e. there are only two alleles per locus, with some rare exceptions for triallelic SNPs [26]. Thus the small number of alleles resulting in a poor biostatistical power per locus has to be compensated by using a large enough number of markers per case. On the other hand, these binary markers have mutation rates which are in the range of 1 in $10^{7}$ to $10^{8}$ meioses and thus practically negligible for kinship cases [27]. To estimate the number of binary markers required to obtain a certain probability for paternity exclusion, the frequency distribution of both alleles at a given locus has the strongest impact, as shown in simulations already published many years ago [28]. To achieve an exclusion probability of $99,997 \%$ in a trio case, 50 SNPs with a minor allele frequency (maf) of 0.5 are required. However, if the maf is only 0.1 , then the exclusion probability is reduced to only $98.6 \%$ [29].

The same, although less pronounced, is true in forensic cases, as not the frequency of the transmitted allele but the genotype frequency has to be considered. In a single source crime scene sample, the match probability using 50 SNPs will be 1 in $10^{12}$ given a maf of 0.1 , and $10^{21}$ given a maf of 0.5 [29]. The major challenge, however, is the analysis of mixtures, as it will be almost impossible to interpret the results if only two alleles can be distinguished. The more persons have contributed to the mixture, the more loci will show the presence of both alleles at each locus, reducing the exclusion power virtually to zero. In such a situation, SNPs with an unbalanced allele distribution might be preferable where a maf $<0.1$ would increase the chance of individual identification, but would require a larger set of loci to increase the chance of observing rare genotypes.

An alternative approach having received a lot of attention by the genomic research community has been proposed recently by Homer et al.[30], who have used high-density SNP genotyping microarrays with more than 500,000 markers to demonstrate the ability to accurately and robustly determine whether individuals are present in a complex genomic DNA mixture (of e.g. more than 4 persons, which is difficult to resolve even using STR markers). The authors claimed to be able to identify the presence of genomic DNA of specific individuals within a series of highly complex genomic mixtures, including mixtures where an individual contributes less than $0.1 \%$ of the total genomic DNA, and suggested that their findings would shift the perceived utility of SNPs for identifying individual trace contributors within a forensics mixture. From a practical point of view, however, the authors appear to have overlooked the fact that forensic mixtures are not 'clean', i.e. they can be highly imbalanced regarding the proportions of individual contributions, and may be subjected to DNA degradation which could render the underlying statistical approach invalid. The problem of not taking into account the mixture proportions has been formally shown in a rebuttal by Egeland et al. [31], who have demonstrated both in simulation experiments as well as using laboratory results from microarray typ- ing experiments of mixtures composed from 2-5 contributors with variable proportions that the statistical approach by Homer et al. [30] fails to make correct predictions.

For the forensic application, four different categories of SNPs can be distinguished based on their field of application as well as their chromosomal location and linkage status: identity-testing SNPs (to connect a crime stain to a suspect); lineage-informative SNPs (typically Y-chromosomal SNPs to define haplogroups); ancestry-informative SNPs (for the prediction of the biogeographic ancestry of an unknown stain donor); and phenotype-informative SNPs (to make inferences about the externally visible physical traits of an unknown stain donor) [32]. It is beyond the scope of this review to cover all aspects of the currently emerging new applications of forensic SNP typing; thus only the aspects regarding identity testing have been addressed here, and more information can be found in other publications [33-38].

During the last few years, a number of SNP marker sets have been described in the literature suitable for identity and kinship testing, and covering about 30-50 loci with balanced allele distributions aiming at maf $>0.3$ in the major populations [39-42]. The currently most popular noncommercial SNP multiplex was developed by the SNPforID consortium and is based on a single 52-locus PCR multiplex, followed by two 23- and 29-plex typing reactions based on the 'single base extension' (SBE) concept (also termed 'minisequencing') [43, 44]. The advantage of this method is that the minisequencing extension products can be separated by capillary gel electrophoresis and identified by fragment length and color of the fluorochrome-labeled single-stranded extension products - a technology available in all forensic genetic laboratories. Using the SBE method, numerous population studies have been performed according to criteria established by recommendations of the International Society for Forensic Genetics (ISFG) [45], and the SBE method for SNP typing has also been validated for routine application [46]. SNP allele frequency data collections are available from internet resources for many populations using the 'SNPforID browser' (http:// spsmart.cesga.es/snpforid.php) [47] or by searching the 'ALlele FREquency Database - ALFRED' (http://alfred.med. yale.edu/) [48, 49]. In kinship testing, it has already been convincingly demonstrated that ambiguous cases, either with complex scenarios or in deficiency cases where one or more mutations resulting in inconclusive evidence, could be resolved by adding the typing results of a SNP multiplex [5052]. Additional case examples are described in some of the articles in this issue.

In contrast to SNPs, indel markers are characterized by sequence length variation due to the presence or absence of a single short sequence motif at a given locus; these markers account for up to $5 \%$ of known polymorphisms in humans [53]. Indels can easily be typed by fragment length analysis if one of the PCR primers is fluorochrome-labeled. Both noncommercial indel marker sets and also a commercial multiplex 
have already been described for routine applications [54-58]. It can be expected that both SNPs and indels will be more frequently used in paternity and kinship testing. At present, such marker kits are mainly applied in situations where one or more suspected mutations have been observed using STR loci so that additional evidence has to be obtained without running the risk of observing another mutation. Nevertheless, STRs will remain the 'work horse' for the time being, and in particular for forensic casework where STR-based national databases exist that demand compatibility [59]. In kinship testing, the situation is different and more flexible, as compat- ibility with existing data is only a minor issue when older cases have to be re-analyzed. However, technology and markers might change more easily if economically attractive alternatives to capillary based fragment length analysis will become available, in particular when the powerful 'next generation' DNA sequencing are becoming more affordable.

\section{Disclosure Statement}

The author did not provide a conflict of interest statement.

\section{References}

1 Jeffreys AJ, Wilson V, Thein SL: Individual-specific ,fingerprints' of human DNA. Nature 1985; 316:76-79.

2 Jeffreys AJ, Wilson V, Thein SL: Hypervariable ,minisatellite regions in human DNA. Nature 1985;314:67-73.

3 Sullivan KM, Walton A, Kimpton C, Tully G, Gill P: Fluorescence-based DNA segment analysis in forensic science. Biochem Soc Trans 1993;21:116120

4 Jobling MA, Gill P: Encoded evidence: DNA in forensic analysis. Nat Rev Genet 2004;5:739-751.

5 Tully G, Sullivan KM, Gill P: Analysis of 6 VNTR loci by 'multiplex' PCR and automated fluorescent detection. Hum Genet 1993:92:554-562.

6 Schneider PM, Martin PD: Criminal DNA databases: the European situation. Forensic Sci Int 2001;119:232-238

7 Martin PD, Schmitter H, Schneider PM: A brief history of the formation of DNA databases in forensic science within Europe. Forensic Sci Int 2001;119:225-231.

8 The Innocence Project: Facts on Post-Conviction DNA Exonerations. Available from www.innocenceproject.org/Content/Facts_on_PostConviction_ DNA_Exonerations.php (last accessed May 4, 2012).

-9 Hallenberg C, Morling N: A report of the 1997, 1998 and 1999 Paternity Testing Workshops of the English Speaking Working Group of the International Society for Forensic Genetics. Forensic Sci Int 2001;116:23-33.

10 Hallenberg C, Morling N: A report of the 2000 and 2001 paternity testing workshops of the English speaking working group of the international society for forensic genetics. Forensic Sci Int 2002;129: 43-50.

11 Morling N, Allen RW, Carracedo A, Geada H, Guidet F, Hallenberg C, Martin W, Mayr WR, Olaisen B, Pascali VL, Schneider PM; Paternity Testing Commission of the International Society of Forensic Genetics: Paternity Testing Commission of the International Society of Forensic Genetics: recommendations on genetic investigations in paternity cases. Forensic Sci Int 2002;129:148-157.

$\checkmark 12$ Gjertson DW, Brenner CH, Baur MP, Carracedo A, Guidet F, Luque JA, Lessig R, Mayr WR, Pascali VL, Prinz M, Schneider PM, Morling N: ISFG: Recommendations on biostatistics in paternity testing. Forensic Sci Int Genet 2007;1:223-231.

13 Jobling MA, Tyler-Smith C: The human Y chromosome: an evolutionary marker comes of age. Nat Rev Genet 2003;4:598-612.
14 King TE, Ballereau SJ, Schürer KE, Jobling MA: Genetic signatures of coancestry within surnames. Curr Biol 2006;16:384-388.

15 Willuweit S, Roewer L: Y chromosome haplotype reference database (YHRD): update. Forensic Sci Int Genet 2007:1:83-87.

16 Szibor R: X-chromosomal markers: past, presen and future. Forensic Sci Int Genet 2007;1:93-99.

17 Hering S, Edelmann J, Augustin C, Kuhlisch E, Szibor R.: X chromosomal recombination - a family study analysing 39 STR markers in German three-generation pedigrees. Int J Legal Med 2010; 124:483-491.

18 Butler JM: Genetics and genomics of core short tandem repeat loci used in human identity testing. J Forensic Sci 2006;51:253-265.

19 Wenk RE: Testing for parentage and kinship. Curr Opin Hematol 2004;11:357-361.

20 von Wurmb-Schwark N, Mályusz V, Simeoni E, Lignitz E, Poetsch M: Possible pitfalls in motherless paternity analysis with related putative fathers. Forensic Sci Int 2006;159:92-97.

21 Poetsch M, Lüdcke C, Repenning A, Fischer L, Mályusz V, Simeoni E, Lignitz E, Oehmichen M, von Wurmb-Schwark N: The problem of single parent/child paternity analysis - practical results involving 336 children and 348 unrelated men. Forensic Sci Int 2006;159:98-103.

22 Mályusz V, Poetsch M, Simeoni E, Schwark T, Manfred O, von Wurmb-Schwark N: Zur Problematik der Beurteilung von Geschwisterwahrscheinlichkeiten mittels genetischer Analyse. Arch Kriminol 2006;218:44-54.

23 Jacewicz R, Berent J, Prosniak A, Dobosz T, Kowalczyk E, Szram S: Non-exclusion paternity case with a triple genetic incompatibility. Int Cong Ser 2004;1261:511-513.

24 Sun HY, Li HX, Zeng XP, Ren Z, Chen WJ: A paternity case with mutations at three CODIS core STR loci. Forensic Science International: Genetics 2012;6:e61-e62.

25 Kersbergen P, Van Eede PH, Kraaijenbrink T, Lardy NM, Sijen T, Bakker E, De Knijff P: 'False positive' or true paternity: Investigating one or two STR mismatches by detailed SNP analyses. Forensic Sci Int Genet Suppl Ser 2008;1:518-519.

26 Phillips C: Applications of autosomal SNPs and indels in forensic analysis Forensic Sci Rev 2012;24: 43-62.

27 Amorim A, Pereira L: Pros and cons in the use of SNPs in forensic kinship investigation: a comparative analysis with STRs. Forensic Sci Int 2005;150: $17-21$.
8 Krawczak M: Informativity assessment for biallelic single nucleotide polymorphisms. Electrophoresis 1999;20:1676-1681.

29 Gill P: An assessment of the utility of single nucleotide polymorphisms (SNPs) for forensic purposes. Int J Legal Med 2001;114:204-210.

30 Homer N, Szelinger S, Redman M, Duggan D, Tembe W, Muehling J, Pearson JV, Stephan DA, Nelson SF, Craig DW: Resolving individuals contributing trace amounts of DNA to highly complex mixtures using high-density SNP genotyping microarrays. PLoS Genet 2008;4:e1000167.

-31 Egeland T, Fonneløp AE, Berg PR, Kent M, Lien $\mathrm{S}$ : Complex mixtures: a critical examination of a paper by Homer et al. Forensic Sci Int Genet 2012; 6:64-69.

32 Budowle B, van Daal A: Forensically relevant SNP classes. Biotechniques 2008:44:603-608, 610 .

33 Jobling MA: Y-chromosomal SNP haplotype diversity in forensic analysis. Forensic Sci Int 2001;118: 158-162.

34 Brión M, Sanchez JJ, Balogh K, Thacker C, BlancoVerea A, Børsting C, Stradmann-Bellinghausen B, Bogus M, Syndercombe-Court D, Schneider PM Carracedo A, Morling N: Introduction of an single nucleotide polymorphism-based 'Major Y-chromosome haplogroup typing kit' suitable for predicting the geographical origin of male lineages. Electrophoresis 2005;26:4411-4420.

35 Phillips C, Salas A, Sánchez JJ, Fondevila M, Gómez-Tato A, Alvarez-Dios J, Calaza M, de Cal MC, Ballard D, Lareu MV, Carracedo A; SNPforID Consortium: Inferring ancestral origin using a single multiplex assay of ancestry-informative marker SNPs. Forensic Sci Int Genet 2007;1:273-280.

36 Kidd JR, Friedlaender FR, Speed WC, Pakstis AJ, De La Vega FM, Kidd KK: Analyses of a set of 128 ancestry informative single-nucleotide polymorphisms in a global set of 119 population samples. Investig Genet 2011;2:1.

37 Pulker H, Lareu MV, Phillips C, Carracedo A: Finding genes that underlie physical traits of forensic interest using genetic tools. Forensic Sci Int Genet 2007;1:100-104.

38 Kayser M, Schneider PM: DNA-based prediction of human externally visible characteristics in forensics: motivations, scientific challenges, and ethical considerations. Forensic Sci Int Genet 2009;3:154161.

39 Dixon LA, Murray CM, Archer EJ, Dobbins AE, Koumi P, Gill P: Validation of a 21-locus autosomal SNP multiplex for forensic identification purposes. Forensic Sci Int 2005;154:62-77. 
40 Kidd KK, Pakstis AJ, Speed WC, Grigorenko EL, Kajuna SL, Karoma NJ, Kungulilo S, Kim JJ, Lu RB, Odunsi A, Okonofua F, Parnas J, Schulz LO, Zhukova OV, Kidd JR: Developing a SNP panel for forensic identification of individuals. Forensic Sci Int 2006;164:20-32.

-41 Li L, Li CT, Li RY, Liu Y, Lin Y, Que TZ, Sun MQ, Li Y: SNP genotyping by multiplex amplification and microarrays assay for forensic application. Forensic Sci Int 2006:162:74-79.

42 Krjutskov K, Viltrop T, Palta P, Metspalu E, Tamm E, Suvi S, Sak K, Merilo A, Sork H, Teek R, Nikopensius T, Kivisild T, Metspalu A: Evaluation of the 124-plex SNP typing microarray for forensic testing. Forensic Sci Int Genet 2009;4:43-48.

43 Sanchez JJ, Phillips C, Børsting C, Balogh K, Bogus M, Fondevila M, Harrison CD, MusgraveBrown E, Salas A, Syndercombe-Court D, Schneider PM, Carracedo A, Morling N: A multiplex assay with 52 single nucleotide polymorphisms for human identification. Electrophoresis 2006;27: 1713-1724.

44 Musgrave-Brown E, Ballard D, Balogh K, Bender $\mathrm{K}$, Berger B, Bogus $\mathrm{M}$, B $ø$ rsting $\mathrm{C}$, Brion $\mathrm{M}$, Fondevila M, Harrison C, Oguzturun C, Parson W, Phillips C, Proff C, Ramos-Luis E, Sanchez JJ, Sánchez Diz P, Sobrino Rey B, Stradmann-Bellinghausen B, Thacker C, Carracedo A, Morling N Scheithauer R, Schneider PM, Syndercombe Court: Forensic validation of the SNPforID 52-plex assay. Forensic Sci Int Genet 2007;1:186-190.

45 Schneider PM: Scientific standards for studies in forensic genetics. Forensic Sci Int 2007;165:238 243.
46 Børsting C, Rockenbauer E, Morling N: Validation of a single nucleotide polymorphism (SNP) typing assay with 49 SNPs for forensic genetic testing in a laboratory accredited according to the ISO 17025 standard. Forensic Sci Int Genet 2009;4:34-42.

47 Amigo J, Phillips C, Lareu M, Carracedo A: The SNPforID browser: an online tool for query and display of frequency data from the SNPforID project. Int J Legal Med 2008;122:435-440.

48 Rajeevan H, Soundararajan U, Kidd JR, Pakstis AJ, Kidd KK: ALFRED: an allele frequency resource for research and teaching. Nucleic Acids Res 2012;40:D1010-1015.

49 Kidd KK, Kidd JR, Speed WC, Fang R, Furtado MR, Hyland FCL, Pakstis AJ: Expanding data and resources for forensic use of SNPs in individual identification. Forensic Sci Int Genet 2012;DOI: 10.1016/j.fsigen.2012.02.012.

50 Phillips C, Fondevila M, García-Magariños M, Rodriguez A, Salas A, Carracedo A, Lareu MV: Resolving relationship tests that show ambiguous STR results using autosomal SNPs as supplementary markers. Forensic Sci Int Genet 2008;2:198-204.

51 Børsting C, Morling N: Mutations and/or close relatives? Six case work examples where 49 autosomal SNPs were used as supplementary markers. Forensic Sci Int Genet 2011;5:236-241.

52 Børsting C, Morling C: Reinvestigations of six unusual paternity cases by typing of autosomal singlenucleotide polymorphisms. Transfusion 2012;52: 425-430.

53 Mullaney JM, Mills RE, Pittard WS, Devine SE: Small insertions and deletions (INDELs) in human genomes. Hum Mol Genet 2010;19:R131-136.
54 Pereira R, Phillips C, Alves C, Amorim A, Carracedo A, Gusmão L: A new multiplex for human identification using insertion/deletion polymorphisms. Electrophoresis 2009;30:3682-3690.

55 Pereira R, Pereira V, Gomes I, Tomas C, Morling N, Amorim A, Prata MJ, Carracedo A, Gusmão L: A method for the analysis of $32 \mathrm{X}$ chromosome insertion deletion polymorphisms in a single PCR. Int J Legal Med 2012;126:97-105.

56 Li C, Zhao S, Zhang S, Li L, Liu Y, Chen J, Xue J: Genetic polymorphism of 29 highly informative InDel markers for forensic use in the Chinese Han population. Forensic Sci Int Genet 2011;5:e27-30.

57 Friis SL, Børsting C, Rockenbauer E, Poulsen L, Fredslund SF, Tomas C, Morling N: Typing of 30 insertion/deletions in Danes using the first commercial indel kit--Mentype(R) DIPplex. Forensic Sci Int Genet 2012;6:e72-74.

58 LaRue BL, Ge J, King JL, Budowle B: A validation study of the Qiagen Investigator DIPplex $(\mathrm{R})$ kit; an INDEL-based assay for human identification. Int J Legal Med 2012;DOI: 10.1007/s00414012-0667-9.

59 Gill P, Werrett DJ, Budowle B, Guerrieri R: An assessment of whether SNPs will replace STRs in national DNA databases--joint considerations of the DNA working group of the European Network of Forensic Science Institutes (ENFSI) and the Scientific Working Group on DNA Analysis Methods (SWGDAM). Sci Justice 2004;44:51-53. 